\title{
EL DESTINO DEL PADRE: KÜNSTLERROMAN Y \\ FALOCENTRISMO EN PARADISO
}

\author{
POR \\ ARNALDO CRUZ-MALAVE \\ Fordham University
}

el cristiano puede decir, desde la flor hasta el falo, éste es el dedo de Dios.

José Lezama Lima, Paradiso

En un pasaje de Paradiso, doblemente señalado por la crítica y por el tex to mismo ("Sé que ésas son las palabras más hermosas que Cemí oyó en su vida, ... y que nunca oirá otras que lo pongan tan decisivamente en marcha”, explica el narrador) Rialta aconseja a su hijo José Cemí sobre su destino personal y familiar:

-La muerte de tu padre, pudo atolondrarme y destruirme, en el sentido de que me quedé sin respuesla para el resto de mi vivir, pero yo sabía que no me enfermaría, porque siempre conocí que un hecho de esa totalidad engendraría un oscuro que tendría que ser aclarado en la transfiguración que exhala la costumbre de intentar lo más difícil. La muerte de tu padre fue un hecho profundo, sé que mis hijos y yo le daremos profundidad mientras vivamos, porque me dejo soñando que alguno de nosotros daríamos testimonio al transfigurarnos para llenar esa ausencia.... A mi ese hecho, como te decia, de la muerte de tu padre me dejo sin respuesta, pero siempre he soñado, y esa ensoñación será siempre la raíz de mi vivir, que esa sería la causa profunda de tu testimonio, de tu dificultad intentada como transfiguración, de tu respuesta (OC I, 321-322. Cursivas mías).

El destino del hijo será "intentar lo más difícil": aclarar el "oscuro" creado por la muerte de su padre, José Eugenio Cemí, "transfigurándose" en el "testimomio". Su destino, que también es el destino familiar, consistirá en partir de esa posición de "ausencia" y de falta de "respuesta" en que está sumida la madre desde la muerte del padre, a la transfiguración del testimonio, de la "imagen", del libro. En otro lugar he explicado cómo Lezama concibe la escritura como la

\footnotetext{
${ }^{1}$ José Lezama Lima, Obras completas, tomo I (México, Aguilar, 1975) 322. En adelante cito de Paradiso por el tomo I y de los ensayos por el tomo II. Incluyo las referencias en el texto y abrevio Obras completas a $O C$.
} 
muerte y resurrección del au tor, como la redención y transfiguración del mundo, como un retorno a su "imagen" primitiva, paradisiaca". La "imagen" (con sus evidentes connotaciones biblicas) es, a través de todos sus escritos e intentos de sistematizar una poética, de conformar su "sistema poético del mundo", la meta y el fundamento de toda escritura ${ }^{3}$. Paradiso, cuya clasificación genérica más evidente sería la de Bildungsroman, o más precisamente Künstlerroman ${ }^{4}$, se divide (por lo menos) en dos partes: la primera de éstas constaría de los capítulos que preceden a la muerte del padre, capitulos en que éste capitanea el destino familiar con la "seguridad de su alegría, la elegancia de su voluntad [y] la magia de su ejercitada disciplina intelectual" (OC I, 171); y la segunda, constituida por" los capítulos que siguen, en que su hijo José Cemí, el poeta incipiente, intenta salvar el ámbito materno de la ausencia paterna, del destierro, transfigurándose, como el personaje de Proust, en un libro, en el lenguaje "seminal" (logos spermatikos lo llama Lezama recordándonos la tradición helénica que cristianiza San Agustín) de la "imagen" del padre y del Padre ${ }^{5}$.

La crítica ha recurrido con frecuencia a las palabras con que comienza el ciclo de conferencias, La expresión americana, para explicar la afición lezamiana por lo esotérico, lo recóndito y lo arcano: "Sólo lo difícil es estimulante; sólo la resistencia que nos reta es capaz de enarcar, suscitar y mantener nuestra potencia de conocimiento..." (OC II, 279. Cursivas mías). Pero pocas veces ha interpretado estas palabras refiriéndose al texto mismo a que pertenecen. $L a$ expresión... es el texto precursor de Las eras imaginarias, texto en el que Lezama

\footnotetext{
${ }^{2}$ Sobre el concepto lezamiano de la "imagen", véase mi "Paradiso": una problemática de los ortgenes", Tesis doctoral, Stanford University, 1984.

${ }^{3}$ Consúltense las múltiples tentativas de Lezama por elaborar un "sistema poético del mundo" en ensayos tales como "X y XX", "Las imágenes posibles", "Exámenes" de Analecta del reloj (OC II, 135-182; 214-227); "Introducción a un sistema poético", "La dignidad de la poesía" de Tratados en La Habana (OC II, 393-427; 760-792); "Mitos y cansancio clásico" de La expresión americana (OC II, 279-301); y "Preludio a las cras imaginarias", "A partir de la poesia" y "La imagen histórica" de La canlidad hechizada (OC II, 797-852).

4 Para una definición del Bilalungsroman, efr. Jerome Hamilton Buckley, Season of Youlh: The Bildungsroman from Dickens to Golding (Cambridge, Harvard Universily Press, 1974) y Michacl Beddow, The Ficlion of Humanily (Cambridge, Cambridge University Press, 1982). Para un estudio comparado del género, v. Randolph P. Shaffner, The Apprenticeship Novel (Nueva York, Peter Lang, 1984) y "The Novel of Formation as Genre: Between Great Expeclalions and Lost Illusions ", Genre XII (Fall 1979): 293311. Sobre el Künstlerroman, en particular, v. Maurice Beebe, Ivory Towers and Sacred Founts: The Artist as Hero in Fiction from Goethe to Joyce (Nueva York, New York University Press, 1964).

${ }^{3}$ Sobre el concepto del logos spermatikos en Lezama, v., por ejemplo, Centro de Invesligaciones Literarias, "Interrogando a Lezama Lima" en Pedro Simon, ed., Recopilación de textos sobre José Lezama Lima (La Habana, Casa de las Américas, 1970) 32.
} 
expone por primera vez una teoría total de la historia, que la articula a ésta con la escritura, organizándola en "eras imaginarias" o "eras donde la imago se impuso como historia" (286). Es en el contexto de esta teoria total de la historia que Lezama define "lo difícil" no sólo como "lo sumergido ... en las aguas maternales de lo oscuro" o"lo originario sin causalidad, antítesis o $\log o s "$, sino, además, como "la forma en devenir en que un paisaje va hacia un sentido, una interpretación o una sencilla hermenéutica, para ir después hacia su reconstrucción ... que es su visión histórica" (279). Aludiendo al Génesis y al concepto pitagórico de la creación, formulado por Platón en el Timeo, Lezama concibe "lo difícil" como "la forma en devenir", el movimiento, de lo amorfo primigenio, "las aguas maternales", hacia el logos, la interpretación, el sentido, la "imagen" que fundamenta toda visión histórica y toda hermenéutica. "Lo difícil" es, pues, la dinámica misma de la poiesis y de la historia ${ }^{6}$. En otro lugar Lezama ha definido la poesia sucintamente como el desplazamiento de la metáfora hacia la "imagen":

Yo creo que la maravilla del poema es que llega a crear un cuerpo, una sustancia resistente enclavada entre una metáfora, que avanza creando infinitas conexiones, y una imagen final que asegura la pervivencia de esa poiesis ${ }^{\text {. }}$.

Así como el poema avanza entre metáforas hasta crear una "imagen" final que se constituye en "cuerpo" o "sustancia resistente"; en lo histórico, cualquier paisaje cultural, cualquier número de datos culturales, por diversos que sean (en La expresión... se dan como ejemplos las ilustraciones de los hermanos Limbourg, lienzos de Van der Weyden, Van Eyck y Simone Martini, la expresión "puerta que se abre hacia afuera" del Yi King y la leyenda Tacquea sobre el origen del fuego en unas tribus ecuatorianas), pueden actuar como metáforas y llegar a constituir una "imagen" que los resuma, conformando una visión histórica (279-283). Para Lezama la historia es esencialmente un inmenso texto cuyos hechos son metáforas organizadas en "imágenes" o núcleos que él denomina "eras imaginarias".

El llamado de Rialta a José Cemí a cumplir su destino intentando "To más difícil" citado anteriormente, concibe, de igual manera, "To difícil" como el movimiento de la oscuridad materna a la transfiguración, de la falta de respuesta de la madre a la "imagen" recobrada del padre y el destino familian" por medio del testimonio, del libro, en que se convierte el hijo. En su llamado

\footnotetext{
${ }^{6}$ Sobre el concepto lezamiano de la historia, v. mi "Licario y la ficción de la historia: un ejemplo", Sin Nombre XIII, 4 (jul.-sept. 1983): 45-64.

3 Armando Alvarez Bravo, "Orbita de Lezama Lima" en Simón, 57.

9 Sobre las "eras imaginarias", v. especialmente "Preludio a las eras imaginarias" $(O C$ II, 797-820), "La imagen histórica" (OC II, 843-852), "Las eras imaginarias: los egipcios (OC II, 864-890) y "Las eras imaginarias: la biblioteca como dragón" (OC II, 890-925).
} 
se unen resurrección, poiesis e historia. Su concepto de "To difícil" se aclara, en los párrafos que preceden al pasaje citado, al distinguir entre dos clases de peligros:

Oyeme lo que te voy a decir: No rehuses el peligro, pero intenta siempre lo más dificil. Hay el peligro que enfrentamos como una sustitución, hay también el peligro que intentan los enfermos, ese es el peligro que no engendra ningún nacimiento en nosotros, el peligro sin epifańa. Pero cuando el hombre, a través de sus días ha intentado lo más difícil, sabe que ha vivido en peligro, aunque su existencia haya sido silenciosa, aunque la sucesión de su oleaje haya sido manso, sabe que ese día que le ha sido asignado para su transfigurarse, verá, no los peces dentro del fluir, lunarejos en la movilidad, sino los peces en la canasta estelar de la eternidad (OC I, 321. Cursivas mías).

"Intentar lo más dificil" es escoger entre "el peligro que intentan los enfermos, ... peligro que no engendra ningún nacimiento en nosotros, ... peligro sin epifanía", y el peligro que lleva a la transfiguración y la resurrección. Es optar a favor del segundo, ascendiendo, como en el Génesis, el Timeo y el pasaje citado de La expresión..., del "oleaje" de la vida, de las aguas primigenias, a la visión (de cara a cara, según San Pablo $^{9}$ ) de la eternidad. Aludiendo a la imagen cristiana de la resurección como pesca, "lo difícil" es el movimiento de los peces en el agua, "lunarejos en la movilidad", hacia la "canasta estelar [inmóvil] de la eternidad". En el discurso de Rialta el peligro mismo no es malo: "No rehuses el peligro...". Lo malo es el peligro que consiste en permanecer en el agua sin ascender a la transfiguración. El destierro, el "oleaje" de la vida, la inmersión en las aguas maternas, no son malos sino necesarios y provechosos, si conllevan al final a la resurrección y la epifania, a un "nacimiento en nosotros".

Muy reveladoramente el llamado de Rial ta reaparece en la intervención de José Cemí en el famoso diálogo a lo platónico, del capítulo XI, sobre el homosexualismo. Al comentar el encuentro de Ulises con su madre en el Hades, Cemí recuerda las palabras de Rialta: "Vive en el peligro de obtener lo más difícil" (OC I, 374). El comentario de Cemí se propone, en este diálogo, ubicar el pecado contra natura (el homosexualismo) dentro del contexto más amplio de lo pecaminoso en Santo Tomás de Aquino. Basándose en éste, Cemí distingue entre dos clases de pecado: el "amor desordenado de la muerte, ... que excluye la participación en el misterio de la Suprema Forma" y el pecado que consiste en ir "por la oscuridad a participar en la forma, en la luz" (373). Así como para Rialta el peligro en sí no es malo sino el peligro que no lleva a la transfiguración, para José Cemí el pecado mismo no es condenable, sino el pecado que no termina en la participación en la Suprema Forma. Siguiendo el razonamiento teleológico de Santo Tomás, para quien lo pecaminoso es, en esencia, lo desordenado, el acto que no se integra al final al orden natural cuyo telos es

9 1 Corintios $13,12$. 
Dios ${ }^{10}$, Cemi argumenta que el descenso a la muerte, al infierno, a la "oscuridad descensional y fria", a la "placenta creadora de la noche" (373), a la matriz, a lo materno, es tolerable si se asciende al final a la "luz germinativa", la luz paterna (OC I, 374). Aludiendo quizás a la metáfora mallarmeana que concibe la fuente creadora que subyace las letras como una oscura entidad femenina ataviada con una "jupe ${ }^{m 1}$, él afirma que la noche puede ser creadora como una "placenta" y caer sobre el hombre como un "sayón", o fértil y "caer sobre el árbol prestándole la fluencia inmóvil" (373), si el descenso a ella es parte de un ascenso general a la luz. Existen, según Cemí, "los hombres que van por la oscuridad a participar en la forma"; pero existen también "los insuficientes, aquellos que van por la luz besando como locos las estatuas griegas de los lanzadores de discos, hasta hundirse en la oscuridad descensional y fria" (373). La noche, la oscuridad, el infierno, se identifican aqui, como en el discurso de Rialta, con la madre; y el homosexualismo se concibe, como en Freud, como la identificación del hijo con la madre y su negativa a separarse del cuerpo materno'

${ }^{30}$ El concepto de lo pecaminoso en Santo Tomás de Aquino está ligado a su concepto del hombre como un ser cuya finalidad es, por naturaleza, Dios. Los hombres, el universo, todo tiende hacia este telos. Conforme a este fin, el concepto de la moral que desarrolla Santo Tomás es, usando un lenguaje aristotélico, teleológico. Así los hombres buscan "actualizar" sus "polencialidades", perfeccionarse moralmente, y el fin de esta perfección moral, el "bien supremo" que buscan, es Dios. En la medida en que una acción humana se desvía de este fin, se desvía de la ley "natural" moral que dictamina que todo tiende hacia el fin divino, esa acción es "contra natura" y pecaminosa. En la medida en que una acción conduce al fin que es Dios, es buena. Summa Teológica I-II, I, 17, 18 y 20 . También cfr. F. C. Copleston, Aquinas (New York, Penguin Books, 1955), en particular, "Man (2): Morality and Socicty", 199-242.

"Es probable que el símil lezamiano "se han quitado como un sayón la placenta creadora de la noche" (OC I, 373) provenga de la sigu iente cila mallarmeana:

Il doit y avoir quelque chose d'occulte au fond de tous, je crois décidément à quelque chose d'abscons, signifiant fermé et caché, qui habite le commun: car, sitôt cette masse jetéc vers quelque trace que c'est une réalité, existant, par exemple, sur une feuille de papier, dans tel écrit - pas en soi- cela qui est obscur: elle s'agite, ou ragan jaloux d'attribuer les ténèbres a quoi que ce soit, profusément, flagramment.

Sa credulité vis-à-vis de plusicurs qui la soulagent, en faisant affaire, bondit à l'excess: et le suppôt d'Ombre, d'eux désigné, ne placera un mot, dorénavanl, qu'avec un secouement que c'ail été elle, l'enigme, elle ne tranche, par un coup d'évenlail de ses jupes: "Comprends pas!" - l'innocent annonçât-il se moucher ("Le Mystère dans les lettres", Quures compleles [Paris, Gallimard, 1945] 383. Cursivas mías).

Tanto Mallarmé como Lezama, en el discurso de Cemí citado en el texto, identifican la fuente creadora que subyace las letras, la escritura, como u na entidad oscura y femenina. Para una discusión de este pasaje dentro del contexto de la obra de Mallarmé, v. Julia Kristeva, La Révolution du langage poélique (Paris, Edilions du Seuil, 1974) 29-30.

${ }^{12} \mathrm{La}$ vá principal al homosexualismo es, scgún Freud, la de la identificación del niño con la madre como defensa contra el incesto o el excesivo amor por ella. Esta se expone en el ensayo, "Leonardo da Vinci and a Memory of His Childhood [Un recuerdo de la infancia de Leonardo da Vinci]", Standard Edition of The Complete Psychological Works of Sigmund Freud, XI (Londres, The Hogarth Press and the Institute of Psycho-Analysis, 1957) 59-137. 


\begin{abstract}
El hombre que ve claro en lo oscuro, jamás podrá estar dañado, pero el que ve oscuro en lo claro, jamás tendrá misterio sexual, haga lo que haga, al cobrar conciencia de ese acto tendrá una culpabilidad morosa, que es la única cosa que logra erotizarlo. Siente la culpabilidad, la presunta culpabilidad que sólo está en él, del acto de la madre al engendrarlo. Siente en frío, pu diéramos decir, el acto de la madre al guardarlo en su interior, $y$ se vuelve pasivo, entregado, abrazado a un fantasma que él hizo culpable, arrancando con una espada esa falsa chispa fantasmal de un cuerpo cuya semilla permanecerá siempre en la gloria (373).
\end{abstract}

En la intervención de Cemí, como en todo Paradiso, el homosexualismo no se define como una sexualidad diferente a la heterosexual, sino como una fijación del desarrollo "normal" de la sexualidad, como una resolución infeliz del complejo de Edipo. Esto es evidente en la alusión que hace Cemí, en el diálogo, a Edipo castigado y ciego al final de la obra de Sófocles: refiriéndose a los "insuficientes" que prefieren la oscuridad materna, Cemí afirma: "Pero estos desdichados ni siquiera se acogen a la sentencia de Edipo: "jah oscuridad, mi luz!..." "(373). Estos "insuficientes" que prefieren la oscuridad materna, no son como Edipo en su hora final cuando, revelado su delito, se saca los ojos, convirtiendo su ceguera en luz, en anagnórisis, sino como Edipo antes de la revelación y el arrepentimiento. En otro lugar, otro personaje, Foción, relata la historia de un pelirrojo homosexual, cuyo "desvío" consiste en tener "un Edipo ... tronado" (OC I, 494). Si bien hay, en el discurso de Cemí y en todo Paradiso, una condenación del homosexualismo o del homosexual como categoria ontológica que es evidente, según han señalado algunos críticos [Reynaldo González, Margarita Junco Fazzolari, Gustavo Pérez Firmat y Gustavo Pellón ${ }^{13}$, en la valoración negativa de personajes como Foción, Martincillo, Baena Albornoz y el novato Leregas; en Paradiso el homosexualismo no sólo es una ontología, sino también, como en Freud, parte de un proceso general que es susceptible de fijarse en la identificación con lo materno o de rebasarse en las asunción de lo fálico, de llevar también a la "luz germinativa", a la Suprema Forma; proceso por el cual pasan todos los personajes, incluso aquéllos a quienes Cintio Vitier ha llamado los "conductores de los contenidos axiológicos" o éticos de la novela ${ }^{14}$. el Coronel, el tio Alberto, José Cemí y Fronesis ${ }^{15}$. Por tanto, en

${ }^{13}$ Margarita Junco Fazzolari, Paradiso y el sistema poélico de Lezama Lima (Buenos Aires, Fernando García Cambeiro, 1979) y Gustavo Pérez Firmat, "Descent into Paradiso: A Study of Heaven and Homosexuality", Hispania 59 (may 1976): 247-257. Para una interpretación distinta, no ontológica, de la importancia del homosexualismo en Paradiso, a nivel del discurso, v. Enrique Lihn, Paradiso Lectura de conjunlo (México: Universidad Nacional Autónoma, 1984) 37-76.

14 Sobre la resolución del complejo de Edipo, vease "The Development of the Libido [Desarrollo de la libido]", The Complete Psychological Works of Sigmund Freud, XVI (1963) 320-338.

${ }^{15}$ Sobre la identificación del complejo de Edipo con la adquisición del lenguaje en Lacan véase "Function and Field of Speech and Language (Función y campo del discurso y el 
su intervención en el diálogo, Fronesis distingue entre los homosexuales en que hay, como en los "insuficientes" del discurso de Cemi, un "menoscabo de la sexualidad" (OC I, 360) y los que, como César, están en el "centro de una esfera vital habitada en todas sus irradiaciones" (361), y concluye que sólo está viciado el hombre que insiste en "un solo sentido" (367); el que, en lugar de constituirse en "centro de prodigiosa concurrencia" (367), de reabrirse a la "diversidad de los sentidos" (367), se fija (en las "aguas ... de espiritu maternal" [362]) y no participa del movimiento ascensional de la escala animal de las aguas a la tierra, de la tierra a la infinidad, del "ángel caido ... [a]l esplendor de la resurrección de los cuerpos" (367).

El llamado de Rialta a Cemí a "intentar lo más difícil" es, pues, dentro de este contexto del diálogo sobre el homosexualismo, un llamado a superar la identificación con la oscuridad materna, a resolver su complejo de Edipo felizmente, ascendiendo de lo infernal materno a lo fálico, al Padre, a la "luz germinativa". Así su llamado se equivale, en la intervención de Cemí, al que hace la madre de Odiseo a su hijo en el Hades:

La madre de Odisco se pierde en el valle de las sombras gimientes, ires veces se le acerca para abrazarla, pero la madre huye, hasta que al fin le dice sus descos. "Procura volver lo anles posible a la luz, aprende eslas cosas y relálalas luego a tu esposa." Cemi hizo una pausa, detenido por el recuerdo de las palabras de su madre: "Vive en el peligro de obtener lo más dificil." La única manera de ascender del infierno, llevando la espiga de trigo, el bastos coloreado de hojas y abejas, cuando la madre hablando desde su muerte, desde las profundidades del sombrío Hades, se vuelve esquiva a las prolongaciones del hijo en las tinicblas, quiere huir del hijo para que el hijo regrese a la luz. Cuando el hijo desciende a las profundidades, para ver en el espejo de la sangre negra el rostro de la madre, la madre huye, prefiere la ausencia del hijo, la ascensión del hijo a la luz germinativa (OC I, 374. Cursivas mías).

Como en Freud, la asunción de lo fálico por parte del hijo (representada aquí con la metáfora doblemente heroica de Hércules ascendiendo del infierno, victo. rioso, con el "bastos coloreado de hojas y abejas", y de Cristo resurrecto, "llevando la espiga de trigo", según sus palabras en el evangelio de San Juan: "De cierto, de cierto os digo, que si el grano de trigo no cae en la tierra y muere, queda solo; pero si muere, lleva mucho fruto" $[12,24]$ ), conlleva no sólo la separación del cuerpo materno, sino también la reorientación del amor por la

lenguaje]", Ecrits: A Selection (Nueva York, W.W. Norton and Company, 1977) 66-67 [Lrad. del francés al inglés de Alan Sheridan]; Anila Lemaire, Jaques Lacan (Londres, Routledge and Kegan Paul, 1977) y John P. Muller y William J. Richardson, Lacan and Language (Nueva York, International Universities Press, 1982) 67-122. Para una crítica de esta interpretación de los fenómenos lacanianos, véase Monique DavidMenard, "Lacanians against Lacan", Social Texl 6 (Fall 1982): 86-111 [trad. del ingles al francés de Brian Massumi]. 
madre hacia un objeto de amor aceptable ${ }^{16}$ en el comentario de Cemí la madre de Odiseo, no sólo incita a éste a abandonar la oscuridad materna para ascender a la luz, sino también a "aprende[r] estas cosas [que él ve en el infierno] y relata[rlas] luego a [s] esposa". El fin de su llamado es, pues, la asunción de lo fálico y la restitución del heterosexualismo; la vuelta a la luz paterna y a la esposa. Como en el discurso de Rialta que citamos al principio, el ascenso del hijo a la luz, su asunción de lo fálico, es, a la vez, un acto de resurrección y de poiesis : el hijo asciende a la luz como el Cristo-Hércules que ha vencido el infierno, a "relatar" lo que ha visto. La asunción de lo fálico en que se resuelve el complejo de Edipo se identifica aqui entonces, como en Lacan, con el lenguaje, la escritura ${ }^{17}$. El llamado de Rialta a Cemí a "intentar lo más difícil" también es un llamado a acceder al orden fálico de la escritura, al logos, al lenguaje "germinativo" o seminal del Padre.

En Paradiso, como en otros Künstlerromane (por ejemplo, A la recherche du temps perdu y A Portrait of the Artist as a Young Man), la asunción de la hombría por parte del niño coincide con su iniciación en el mundo de la escritura, de la poesía. Su paso a la hombría describe, como en tantos otros Bildungsromane, el movimiento de sus tensiones edípicas iniciales a la asunción de lo fálico y la afirmación de otra paternidad: estas tensiones, que pueden manifestarse en el rechazo explícito de la figura paterna (por ejemplo, en Wilhelm Meister, Le Rouge et le noir, A Portrait... y The Mimic Men) o implicitamente en la ausencia o muerte del padre (por ejemplo, en Great Expectations, Don Segundo Sombra, In the Castle of My Skin, Los rios profundos, La vispera del hombre, La Habano para un infante difunto y Paradiso), se resuelven, en el transcurso del aprendizaje del niño, en el desplazamiento o sustitución del padre real (en Paradiso, el Coronel) por otra figura paterna (en Paradiso, Licario, el poeta arquetípico) con la que se identifica el niño o, por medio de la cual, éste asume su vocación, su puesto en el mundo ${ }^{18}$. Este sustrato edípico que define el Bildungsroman, ese conflicto entre "padres e hijos", para citar el subtítulo de un ejemplar del género ${ }^{19}$, no ha escapado a la crítica de Paradiso, que podría dividirse entre los que, como Julio Ortega, ven en éste una "alabanza" al padre, al Creador ${ }^{20}$ y los que, como Enrico Mario Santi, ven en él una práctica textual afirmativa del

\footnotetext{
${ }^{16}$ Sobre la importancia de la paternidad como elemento estructural del Bildungsroman, v. Buckley, pp. 14-20. Para un estudio de la paternidad y la narracion, consúllese Roberl Con Davis, ed., The Fictional Father. Lacanian readings of the Text (Amherst, The University of Massachusetts Press, 1981).

${ }^{17}$ George Meredith, The Ordeal of Richard Feverel: A History of Father and Son (1859). Para un análisis de la paternidad de csta novela, v. Buckley, pp. 63-91.

${ }^{18}$ La contemplación y la fiesia (Caracas, Monte Avila, 1969) 116.

19 "Parridiso" en Justo C. Ulloa, José Lezama Lima: Textos Crílicos (Miami: Ediciones Universal, 1979) 108. Para un estudio del sustrato edípico en Paradiso desde una perspectiva parecida a la de Santf, v. Lihn, ob. cit.

20 Freud, XIII (1955) 141-146.
} 
parricidio que consiste en "citar mal, [en] repetir el original con cambios, [en] cuestionar la autoridad y la anterioridad sin remordimientos: [en] ser Edipo sin complejo" ${ }^{21}$. Si bien es cierto que Paradiso expresa tensiones edípicas, parricidas, tanto a nivel temático como de la práctica textual misma, es cierto también que en él se valora, como veremos, lo paterno en tanto función, en tanto Ley, que, como en Tótem y tabú, sólo se mata al padre real para sustituirlo por la Ley paterna ${ }^{22}$, por lo que Lacan llama el significante del $\mathrm{Falo}^{23}$.

La identificación del complejo de Edipo, del proceso por el cual el hijo se identifica con el padre, accede a lo fálico, con el proceso por el cual se accede al lenguaje o la escritura, es el tema de una secuencia de cinco relatos que analizaremos en adelante ( $O C \mathrm{I}, 176-188)$. En estos relatos, que llamaremos relatos órficos porque hay en todos una inmersión en el agua que se asocia con un descenso al infierno, José Cemí intenta resolver sus tensiones edípicas, a la vez que accede al libro, a la escritura. Se generan todos a partir de un relato inicial en el que el Coronel trata de enseñarle a nadar a su hijo (176-178). El Coronel lo manda a tirarse al agua y aguantarse de su dedo índice, "hecho a ejercer la autoridad, fuerte como un enano, que hiciese un personaje en la torre de Londres" (177; cursivas mías), y cuando cree que él ya puede nadar solo, sin el apoyo de su dedo, le retira la mano. Pero su hijo, sin el "ancla" de seguridad del dedo paterno, se hunde, y es rescatado por un marinero que vigila a los nadadores desde la orilla.

Los relatos que siguen repiten esta misma trama (o trauma). El segundo relato (178-179) es la descripción de una pesadilla recurrente en la que Cemí desciende al "boquete oscuro" del túnel del Castillo del Morro que dirige su padre. Esta pesadilla tiene dos desenlaces distintos: en el primero, Cemi es rescatado del túnel por unas "largas varas con tridentes"; en el segundo, rueda por el túnel hasta llegar al mar, atraviesa las aguas donde "los tiburones dormidos flotan ininterrumpidos" y es rescatado al otro lado por una pequeña embarcación, cuyos tripulantes se acercan con una lámpara, lo reconocen y comienzan a secarlo. En el tercer relato (180-181), el Coronel, que intenta

\footnotetext{
${ }^{21}$ Lacan define así el significante del Falo: "The Phallus is the privileged signifier of that mark in which the role of the logos is joined with the advent of desire [El falo es el significante privilegiado de esa marca en la cual el rol del logos se junta con el advenimiento del deseo]" ("The signification of the Phallus" 287). El falo es el significante paterno privilegiado que viene a ocupar el lugar, el vacio, la falla (le manque a être, dice Lacan), creados por las sucesivas separaciones, enajenaciones del ser, en el proceso de la constitución del sujeto: separación del cuerpo de la madre, separación de sí mismo en la identificación con la imagen, con el Otro, en el Estadio del Espejo, en la identificación con las categorias simbólicas (socio-lingüísticas) que lo definen al acceder al lenguaje. En los cinco relatos que analizaremos en adelante veremos el desplazamiento del padre real por el significante del Falo.

${ }^{22}$ Para un análisis distinto de estos relatos, v. Ortega, 82-86.

${ }^{23}$ Sobre la distinción "pene" "falo", véase "The signification of the Phallus", 285.
} 
resarcirse de "la deficiencia bronquial" de su hijo asmático, ordena a su hija Violante nadar en la piscina improvisada del Castillo del Morro: "un gran pozo, con una gárgola acuosa en cada uno de sus lados", de "profunidad avérnica" (180). Ya en medio de la piscina Violante se empieza a hundir, y es rescatada por dos asistentes del Coronel con "lanzas varas, terminadas en curvo tridente". "Puesta a horcajadas sobre el tridente", Violante asciende del fondo de la piscina "como una pequeña Eurídice" que, al contrario de la original, ascendiera del infierno al "reino de los vivientes". El Coronel, dueño del tridente, "confundido Poseidón", que se lanza a salvar a su hija, emerge del agua en el momento en que ella es rescatada por sus dos asistentes. El cuarto relato (181-184) consiste en una discusión entre el Coronel y Rialta sobre el asma de Cemí y en la prueba de un nuevo remedio para ésta. El Coronel, que considera que su hijo lo que necesita es un "pinchazo para tranquilizarlo", un "susto que lo cur[e] de sustos", lo manda sumergirse en una bañera helada. Cemí no reacciona positivamente a esta "frigiterapia" del Coronel, que, al contrario, le provoca una nueva crisis asmática. El último relato (184-188) integra todos los elementos importantes de los anteriores en un complicado sueño de Cemí en el que se destacan las dos preocupaciones centrales de aquéllos: la angustia de Cemí por la separaración del "ancla" de salvación del dedo paterno, y su incapacidad para la natación, para atravesar el "boquete oscuro" de las aguas, asociada ésta con su dificultad respiratoria o asma. El sueño de Cemí es un "acuario" en el que él se sumerge. En el "acuario del sueño" el dedo del padre es substituido por un "pez anchuroso, con su rosado ingenuote y navideño", que tira del dedo a Cemí y le imparte su protección, hasta provocar en él la "música acompasada, de fino cálculo, de su nueva respiración" (185). Este pez es substituido, a su vez, por el rosiro de Rialta. Una estrella de mar aparece entonces que se expande y se contrae y se confunde con el rostro materno. Cuando la respiración de Cemí coincide con las expansiones y contracciones de esta estrella de mar materna, se produce un "tegumento blanco" en el que desembarcan enanos de "cabezotas con larguísimas pelambreras" (185). Si recordamos que en el relato inicial el dedo del padre es "fuerte como un enano" (179), podemos interpretar ahora estos enanos del sueño de Cemi como representaciones de ese dedo paterno. Los enanos como "cazadores canadienses" se encaminan a una casa donde Rialta les indica el orden de los asientos en un "conciertogastronómico" que ella dirige. En ese momento Cemí cree ver a Violante en el "boquete infernal" de la piscina del Castillo del Morro del tercer relato. Pero en el fondo del boquerón, del "centro de la tierra, [d]el infierno de los griegos" a que ha descendido Cemí en el sueño, ve, en cambio, el rostro de su madre dirigiendo el festín de los comensales enanos (185). Los enanos comienzan a improvisar taconeos de medidas pitagóricas que vencen los "secretos de la casa nueva" (186). Reemplazando al padre en el cuarto relato, la madre sumerge a su hijo en una bañera, y le echa agua "tibia, aromática, de los más diversos colores" como en un bautismo (186). Los enanos se sientan a la mesa, donde todos los platos contienen un pescado que reproduce 
la faz de Rialta. La reproducción del rostro materno en el festín igastronómico crea un ámbito en el que la respiración dificultosa de Cemí "zafa[..] [por fin] sus cordeles, evaporándose de una sangre desde ese momento tranquilamente eficaz, armoniosa en su irradiación para el mundo exterior" (187). El rostro reproducido de la madre se asemeja a "esos retablos donde todas las figuras remedan el rostro mariano, ... figuras que protegen a la oveja, a los niños y a las nubes" (187). Al despertar del sueño, Cemí se siente "como si sobre sus más oscuras regiones, el mediodía hubiese comenzado a predominar" (187). Su despertar, ascendiendo del "boquete infernal" a la madrugada en que la "retirada de la brumosa y bostezada placenta nocturna, deja a la arcilla y a las piedras de las casas bondadosamente lavadas, un poco más ingenuas", coincide con el encuentro con su padre, quien lo introduce por primera vez al libro (187). Mirando los grabados del libro, Cemi construye su primera metáfora.

Los elementos comunes a estos cinco relatos son: la identificación de la inmersión en el agua con el descenso a un "boquete oscuro" (relato 2, p. 179), a una "profundidad avérnica" (relato 3, p. 180), al "centro de la tierra, el infierno de los griegos" (relato 5, p. 185), a la muerte ("[L]os fantasmas y la muerte [...] asedian [a Cemí] .... Se acuesta muy tranquilo y se despierta como si hubiese salido del infierno", comenta el Coronel en el cuarto relato [182].), al reino de los muertos (relato 3, p. 180), a la madre, a la matriz ("ahora lo que veía [Cemí] en el lecho de aquel boquerón era siempre la cara de su madre sonriéndole" [relato 5, p. 186]), a la "placenta nocturna" (relato 5, p. 187), a la dificultad respiratoria y la incapacidad para "contar" (Cemi "[t]iene como la angustia de quedarse dormido. En el sueño gira, se desespera, quiere escribir en las almohadas. Se acuesta muy tranquilo y se despierta como si hubiese salido del infierno .... Cada sueño que no puede contar lo ahoga, ahí está ya el asma" [relato 4, p. 182; cursivas mías]) y al sueño(relatos 2 y 5 ). Como en los discursos de Rial ta y Cemí, la inmersión en el agua se identifica en estos relatos con el descenso al infierno, la oscuridad, la matriz y la muerte. Inversamente, emerger del agua se identifica con el ascenso a la luz ("En la medianoche una pequeña embarcación comienza a remar hacia Cemí. Sonríen y acercan la lámpara a su cara ..." [relato 2, p. 1791. "Aquel sueño, aquel desfile de enanos pintarrajeados, lo había como aligerado, como si sobre sus más oscuras regiones el mediodía hubiese comenzado a predominar" [relato 5, p. 187]), al alba, a la madrugada (relato 5, p. 187), al despertar (relatos 2,4 y 5), al reino de los vivientes ("puesta a horcajadas sobre el tridente Violante ascendió como una pequeña Eurídice al reino de los vivientes" [relato 3, p. 180]), a la salvación, la resurrección y el perdón ("Desde la puerta del boquete, empiezan los carceleros a introducir largas varas con tridentes, entonces llega el perdón y el despertar" [relato 2, p. 179]), al padre, al libro y el lenguaje metafórico (relato 5).

El tema central de estos relatos es, como en los discursos de Rialta y Cemí, la tensión del hijo por "intentar lo más difícil", por asumir el poder paterno para descender a lo materno y ascender, como un héroe órfico o como Cristo, al padre 
(Padre) y al libro. Las lecciones de natación que le imparte el Coronel a Cemí tienen en ellos el objeto de enseñarle a atravesar el "oscuro boquete" de las aguas maternas y de hacerlo asumir lo fálico, lo paterno. Por tanto contrastan, desde el primer relato, las habilidades natatorias de ambos. Mientras el Coronel señorea sobre las aguas, su respiración parece ordenar el cuchillo de la proa de su canoa, y su dedo índice es el "ancla" que mantiene a Cemí a flote sobre las aguas (relato 1), los intentos de Cemi por nadar terminan repetidas veces en crisis asmáticas (relatos 1, 3 y 4). Este contraste se refleja también en sus habilidades respiratorias. En tanto que el Coronel, al expandir su pecho, "parecia que se fumaba la brisa marina, dilataba las narices, tragaba una cantidad épica de oxígeno, y luego lo iba lanzando por la boca en lentas humaredas"; Cemí "flacucho, con el costillar visible, jadeaba cuando la brisa arreciaba, hasta hacerlo temblar con disimulo" (177).

A través de los cinco relatos el dedo índice del padre se revela como el símbolo mismo de su habilidad natatoria, de su poder fálico para atravesar las aguas maternas. Conforme a la distinción lacaniana, su dedo, "hecho a ejercer la autoridad", no es el "pene" o miembro viril real sino el "Falo", símbolo o significante social de la autoridad del padre o Ley paterna. Esta calidad de símbolo o significante social de su dedo se confirma en el hecho de que, a partir del primer relato, éste se separa de su cuerpo; se independiza; comienza a actuar por si solo; se convierte en ente autónomo susceptible de reproducirse y de ser asumido. En el primer relato el dedo del padre se transforma en el "ancla" de salvación que mantiene a Cemí a flote sobre las aguas. En el segundo su dedo es la "roca saliente" y las "largas varas con tridentes" que rescatan a Cemi del "oscuro boquete" del túnel del Castillo del Morro y, a la vez, el instrumento de su redención y "perdón":

ya traspongo los barrotes que resguardan el túnel, que termina en las cuevas submarinas, me araño, me sangro, al fin encuentro una roca saliente donde encajo mis uñas, que crecen por instantes para salvarme. Desde la puerta del boquete empiczan los carceleros a introducir largas varas con tridentes, entonces llega el perdón y el despertar (179).

En el tercero su dedo, metamorfoseado en tridente, rescata a Violante, "pequeña Eurídice", de la "profundidad avérnica" de la piscina del Castillo del Morro. Así como el tridente representa lá autoridad de Poseidón sobre el mar, este tridente simboliza el poder del Coronel, "confundido Poseidón", para atravesar las aguas. El rescate de Violante constituye también, como en el relato anterior, una resurrección y salvación:

José Cemí vio a su hermana, ya en el fondo de la piscina, vidriada, con los cabellos de diminuta gorgona con hojas de piña. Dos asistentes que habian acudido al sorpresivo surgimiento con unas lanzas varas, terminadas en curvo tridente, que se usaban para la limpieza del fondo de la piscina, comenzaron 
con mágica oportunidad la extracción. Puesta a horcajadas sobre el tridente, Violante ascendió como una pequeña Eurídice al reino de los vivientes. Las piernas con sangre y hojas, con las hojas de yedra húmeda, que asomaban cuando el agua desaparecía y las paredes de cal se amorataban por el esfuerzo de recibir el aire bienvenido (180).

En el quinto su dedo se convierte, como hemos señalado, en los enanos "de cabezotas con larguísimas pelambreras canas" que participan en el "festín gastronómico" que dirige Rialta, en el que en cada plato hay un pescado con su rostro. Siguiendo el ejemplo de estos comensales enanos, el hijo participa en la incorporación del cuerpo materno. Si en los rèlatos anteriores Cemí es el objeto del rescate de las aguas maternas por parte del dedo del padre y sus representantes: èl ancla, la roca saliente y las largas varas con tridentes, aqui se transforma en agente; al unirse a estos enanos, asume él el poder fálico para atravesar lo materno.

Así como el dedo del Coronel se separa, se independiza, se convierte en símbolo, el rostro de Rialta se reproduce en las caras de los pescados que incorporan los enanos y Cemí. Esta reproducción del rostro de Rialta la convierte también en símbolo susceptible de ser asimilado por el hijo sin incurrir en el incesto. Comoen la intervención de Cemí en el diálogo sobre el homosexualismo, el proceso de identificación con lo paterno comporta la abstracción del cuerpo materno en un signo, recuperable por el hijo en otros cuerpos femeninos. Si en el comentario que hace Cemí del descenso de Ulises al infierno, éste asciende del infierno en que se encuentra su madre a la luz en que está su esposa, en el quinto relato Cemi asciende del "centro de la tierra, el infierno de los griegos" (185), en que ve a su madre en el sueño a su imagen reproducida en los platos del festín gastronómico "como en esos retablos, donde ... todas las figuras remedan el rostro mariano [...] en distintos gestos" (187). Al igual que en los discursos de Rialta y Cemí, la identificación con la madre, el descenso a lo materno, son aceptables si al final se resuelven en la asunción de lo paterno y en la orientación del deseo del hijo por la madre hacia otros cuerpos.

Este proceso de abstracción del dedo del padre y el rostro de la madre en significantes, en símbolos de lo masculino (fálico) y lo femenino, respectivamente, corresponde al desenlace del quinto relato, en el que Cemí, al despertar de su sueño, se encuentra con el Coronel, quien lo introduce al libro, a la escritura. Como en las lecciones de natación anteriores, el padre le indica al hijo con su dedo índice los grabados del libro. Sustituyendo el dedo del padre, el hijo empieza a apuntar por si solo los grabados y, adelantándose a la voz de aquéls trastoca metafóricamente los nombres de los dos grabados que aparecen en el libro: el de un bachiller y el de un amolador. De modo que, cuando el Coronel le pregunta qué es un bachiller, Cemí responde inconscientemente con una metáfora que identifica al bachiller con la rueda de un amolador: "Un bachiller es una rueda que lanza chispas, que a medida que la rueda va alcanzando más 
velocidad, las chispas se multiplican hasta aclarar la noche" (188). La sustitución del dedo del padre por parte del hijo, su asunción del poder paterno para indicar, comporta entonces, como en general en los relatos, un proceso de abstracción, un cambio de lo real a lo simbólico, de lo literal a lo figurado.

En los cinco relatos órficos que hemos examinado la resolución de las tensiones edípicas de Cemí, del proceso por el cual él accede a lo fálico, comporta un movimien to de lo material a lo espiritual, de la oscuridad a la luz, del infierno a la resurrección, de la matriz al Falo, de lo real a lo simbólico, lo literal a lo figurado. Como en los comentarios de Rialta y Cemí, en estos relatos el complejo de Edipo se equipara con el proceso de acceso al lenguaje, a la escritura, al libro. Ello se comprueba también en la identificación del asma de Cemí con su dificultàd natatoria, pues no sólo en estos relatos, sino en todo Paradiso, la respiración conforma una poética. La dificultad de Cemí para atravesar las aguas del sueño, equiparada a su asma, se resuelve, como explica el Coronel, con el cuento: "Cada sueño que no puede contar lo ahoga, ahí está ya el asma" (182; cursivas mias). Contar el cuento es resolver el "ahogo" de las aguas y del asma, salvar el espacio materno de las aguas para lograr, como en el quinto relato, una nueva respiración "eficaz [y] armoniosa en su irradiación para el mundo exterior". Armonizar el espacio interior del cuerpo con el espacio exterior, "imagen" o logos divino por medio de la respiración, es la ambición poética de José Cemí, asmático que recuerda a ese otro asmático literario para quien el asma también es una metáfora de la creación poética: el Marcel de $A$ la recherche du temps perdu.

"Intentar lo más difícil", el llamado de Rialta a Cemí, es, a la vez, un llamado a cumplir un destino personal y familiar poético. El complejo de Edipo, el proceso por el cual el hijo se identifica con el padre, accede a lo fálico, conforma una poética y una vocación: Cemí accede al lenguaje figurado, al libro, accediendo a lo fálico, lo paterno; transfigurándose en la "imagen" de su padre muerto y del Padre. Esta identificación del complejo de Edipo con el acceso al lenguaje acercaría à Lezama a Lacan, para quien esa identificación es una de las piedras angulares de su pensamiento. Hay, empero, una diferencia. En Lezama el complejo de Edipo no se identifica con el acceso al lenguaje mismo sino al lenguaje en tanto relato, escritura. Lezama, a diferencia de Lacan, no parece sugerir que es necesario acceder a lo fálico para manejar el lenguaje y las estructuras sociales que de él se derivan; sino, sencillamente, que es necesario acceder a ello para contar o escribir, para manejar los códigos literarios, para entrar en la poesia; que el "sistema poético del mundo" es radicalmente falocéntrico, patriarcal. 